\title{
Quality Metrics of Semi Automatic DTM from Large Format Digital Camera
}

\author{
J. Narendran, P.Srinivas, M.Udayalakshmi, S.Muralikrishnan \\ National Remote Sensing Centre, Indian Space Research Organization, Balanagar, Hyderabad 500037 India \\ narendran_j@nrsc.gov.in
}

KEY WORDS: LFDC, DSM, DTM, Ultracam-D, filtering, Check points, GSD

\begin{abstract}
:
The high resolution digital images from Ultracam-D Large Format Digital Camera (LFDC) was used for near automatic DTM generation. In the past, manual method for DTM generation was used which are time consuming and labour intensive. In this study LFDC in synergy with accurate position and orientation system and processes like image matching algorithms, distributed processing and filtering techniques for near automatic DTM generation. Traditionally the DTM accuracy is reported using check points collected from the field which are limited in number, time consuming and costly. This paper discusses the reliability of near automatic DTM generated from Ultracam-D for an operational project covering an area of nearly $600 \mathrm{Sq}$. Km. using 21,000 check points captured stereoscopically by experienced operators. The reliability of the DTM for the three study areas with different morphology is presented using large number of stereo check points and parameters related to statistical distribution of residuals such as skewness, kurtosis, standard deviation and linear error at $90 \%$ confidence interval. The residuals obtained for the three areas follow normal distribution in agreement with the majority of standards on positional accuracy. The quality metrics in terms of reliability were computed for the DTMs generated and the tables and graphs show the potential of Ultracam-D for the generation of semiautomatic DTM process for different terrain types.
\end{abstract}

\section{INTRODUCTION}

The first decade of the $21^{\text {st }}$ century saw the introduction and operationalization of Large Format Digital Camera (LFDC) for aerial photogrammetry. LFDC has brought in total digital workflow from data acquisition to end product generation and near automatic generation of Digital Surface Model (DSM), Digital Terrain Model (DTM) and orthoimage generation (Nicolas Paparoditis, 2006). It has brought innovations in terms of radiometry, cost free forward overlap images, image matching algorithms, GPU based data processing of large volume of image data (Leberl, 2010). High resolution DTMs, DSMs are increasingly used for flood modeling, disaster applications, Orthoimage generation, terrain visualization, simulators etc., using data from airborne and satellite platforms. The DTMs along with orthoimages provide cost and time effective spatial information for GIS (Baltsavias, 1999).

These products are very useful in decision support systems for critical GIS applications and mostly the products are presented without accurate estimate of its reliability. Reliability of DTM can defined as degree of correctness to which the DTM accuracy has been estimated (Zhilin Li, 1991). Traditionally, the vertical accuracy reporting is based on a set of check points by finding the difference between the elevation from the DTM and to its elevation obtained from independent source of higher accuracy (Maune, 2001a). "The National Standards for Spatial Data Accuracy (NSSDA)" published by Federal Geographic Data Committee recommends distribution of a minimum of 20 check points to reflect the geographical area of interest and the distribution of error in the data set.

The DTM accuracy achievable for different large format digital camera with different resolutions have been studied (Hohle, 2009). In this study the quality metrics like standard deviation, Linear Error at $90^{\text {th }}$ percentile, skewness of DTM generated through semi-automatic process from digital images acquired from Ultracam-D for different terrain types is presented and discussed.

\section{STUDY AREA AND DATASETS}

The three study areas are Rajnandgaon, Durg-Bhilai and Korba towns located in Chhatisgarh state of India (see Fig.-1). The major Land Use / Land Cover types of the study areas are built-up, agriculture, water body etc. In addition to the above, open cast coal mines are seen in Korba and large number of industrial buildings for Durg-Bhilai (Table-1). The digital images the three study areas were acquired from Beechcraft Super King B-200 aircraft using Ultracam-D large format digital camera.

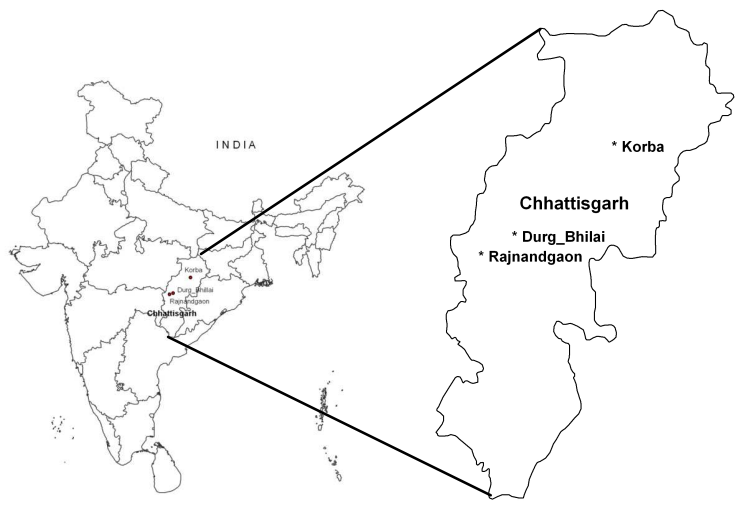

Fig.-1: Three towns of Chhatisgarh state, India 


\begin{tabular}{|c|c|c|c|l|}
\hline S.No. & $\begin{array}{c}\text { Study } \\
\text { Area }\end{array}$ & $\begin{array}{c}\text { Area } \\
(\text { Sq. Km. })\end{array}$ & $\begin{array}{c}\text { Terrain } \\
\text { height } \\
(\mathrm{m})\end{array}$ & Terrain Type \\
\hline 1 & $\begin{array}{l}\text { Rajnan } \\
\text { dagaon }\end{array}$ & 95 & 290 & $\begin{array}{l}\text { Built-up, } \\
\text { mostly Open } \\
\text { areas }\end{array}$ \\
\hline 2 & $\begin{array}{l}\text { Durg- } \\
\text { Bhillai }\end{array}$ & 234 & 280 & $\begin{array}{l}\text { Built-up, } \\
\text { Industrial } \\
\text { areas }\end{array}$ \\
\hline 3 & Korba & 263 & 300 & $\begin{array}{l}\text { Built-up, } \\
\text { Mining areas, } \\
\text { Forest }\end{array}$ \\
\hline
\end{tabular}

Table-1: Terrain types in the study area

\section{OBJECTIVE OF THE STUDY}

The objective of the study is to investigate the performance of the LFDC Ultracam-D for semi-automatic DTM generation and to develop quality metrics in terms of reliability on the resultant DTM for different terrain types in an operational project scenario using large number stereoscopically collected check points in place of traditional field check points which is very limited in number, time consuming and costly.

\section{METHODOLOGY}

The factors which influence the accuracy of the DTM are digital camera characteristics, aerial data acquisition parameters like flying height, GSD, overlaps, GPS reference station for direct georeferencing operations, precise and well defined GCPs for integrated orientation, aerial triangulation and block adjustment, automatic image matching and filtering algorithms. In this study, standard photogrammetric processes and methods are implemented (Fig-2) and are discussed below.

\subsection{Aerial Data Acquisition}

The aerial flight planning is an important step in finalization of the flight parameters in terms of GSD, forward and side laps, catering to the product specifications. The digital aerial images were acquired at $10 \mathrm{~cm}$ GSD with UltracamD at a flying height of $1000 \mathrm{~m}$ above ground level for DTM and orthoimage generation. The salient specifications of the camera are given in Table-2.

\begin{tabular}{|l|c|}
\hline \multicolumn{1}{|c|}{ Parameter } & Specifications \\
\hline Camera Name & Ultracam-D \\
\hline Type & Frame \\
\hline Along Track (Pixels) & 7500 \\
\hline Across Track (Pixels) & 11500 \\
\hline Pixel Size (microns) & 9 \\
\hline Focal Length (mm) & 101 \\
\hline B/H & 0.27 \\
\hline
\end{tabular}

Table-2: Ultracam-D Specifications

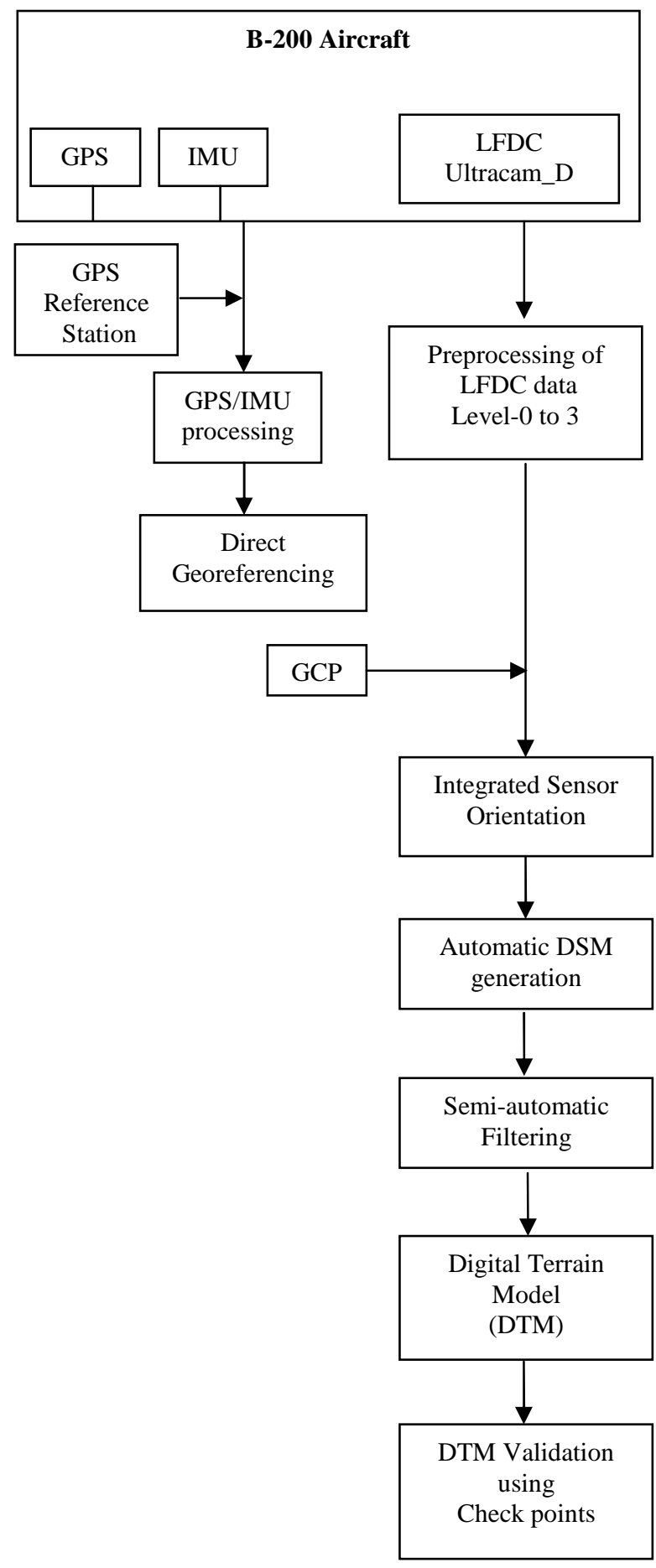

Fig.-2: Flowchart of Photogrammetric processes for DTM generation \& validation

The camera is a calibrated one and the boresight angles between the GPS and IMU is determined using the calibration test field established by NRSC. The preprocessing of the UltracamD images from level-00 to level-3 involves data verification, radiometric correction using calibration files, stitching and pan sharpening of the images is carried out in the Office Processing Centre. 


\subsection{Direct Georeferencing \& Integrated Sensor Orientation}

The photogrammetric processing requires both interior and exterior orientation parameters. The camera is a calibrated one and the boresight angles between the GPS and IMU is determined using the calibration test field established by NRSC. The UltracamD is integrated with Novatel GPS receiver and IGI IMU which provides exterior orientation parameters for direct georeferencing of the images which reduces the number of Ground Control Points (GCPs) for Integrated Sensor Orientation. The airborne GPS data is processed with reference to the GPS reference station in kinematic relative positioning mode using Grafnav and the GPS solution is combined with IMU data using the Aero-office software for the determination of the position of the camera with centimeter to decimeter accuracy and its orientation to better than one-hundredth of a degree.

Further for integrated sensor orientation, GCPs have been collected and processed with reference station in static relative positioning mode and the accuracy of the GCPs are within 2 $\mathrm{cm}$. The block adjustment accuracy for the three study areas namely Rajnandgaon, Korba and Durg Bhilai are less than 1 pixel.

\subsection{DSM Generation}

On completion of the block adjustment digital surface model is generated automatically using image matching algorithm available in Trimble's Match- $T$ software. With the operationalization of digital camera, digital workflow has gained importance and most of the commercial digital photogrammetric workstation have automatic DTM/DSM generation package since manual generation of DTM is operator intensive and time consuming. Normally Area Based Matching and Feature Based Matching (FBM) are main matching techniques used for automatic DTM/DSM generation (Gruen, 2012). The Match-T software uses a hybrid automatic matching algorithm consisting of feature based and least square matching techniques with resultant accuracy of $1 / 3$ and $1 / 10$ of the pixel size respectively and the DSMs of grid size $1 \mathrm{~m} \mathrm{X} 1 \mathrm{~m}$ in urban areas and $3 \mathrm{~m} \mathrm{X} 3 \mathrm{~m}$ in rural areas is generated for the three study areas.

\subsection{Filtering}

The generated digital surface model (DSM) is the maximum altitude at any place with points located on roof of the buildings, tree tops, civil structure tops etc. For topographic mapping, DTM that represents the bare earth is required. The Filtering technique is used to generate DTMs from DSMs based on geometrical reasoning to classify terrain and non-terrain points (Axelsson, P. 2000). Different filter algorithms like morphological filters, progressive densification, surface based filters, segmentation etc., have been developed to extract bareearth from digital surface models from airborne LiDAR and INSAR. (George Sithole, 2004).

In this study Axelsson filter that has been implemented in Terrasolid's Terrascan software was used for filtering the DSM to DTM. Initially a sparse TIN is generated using the low points which are neighbourhood minima and the TIN of the bare earth is progressively densified from DSM based on the criteria set on elevation angle and elevation distance in an iterative process. At the end of each iteration, the TIN of the bare earth is reconstructed and this forms ground surface for the next iteration . The iteration stops when there are no more ground points meeting the threshold or certain desired point density is achieved or if all acceptable points are closer to the surface than another threshold ((Axelsson, P. 1999).

After the automatic filtering process, the DSM was filtered through semiautomatic process and involves manual editing of the DTMs and breakline addition to derive the bare earth and for precisely depicting the terrain. The DTM was edited manually for misclassification off-terrain points in the bare earth surface due lack of texture information, terrain homogeneity, erroneous mass points etc., and breaklines were added manually through stereo methods to exact representation of the terrain. The final interpolated DTM has spatial resolution of $1 \mathrm{~m}$ in UTM projection and WGS-84 datum in planimetry and orthometric elevation in height.

\subsection{Theoretical DTM Accuracy}

The elevation accuracy of the DTM can be calculated using the formula

$$
\sigma_{z}=\frac{h}{b} \odot \sigma_{p}^{*} s_{f}
$$

The same formula for the digital camera is rewritten as given below:

$$
\sigma_{z}=\frac{f}{b^{T}} * \frac{\sigma_{p}}{p_{x}} * G 5 D
$$

Where is sz elevation accuracy, $\mathrm{h}$ is average flying height above ground level, $\mathrm{b}$ is the airbase, sp is parallax measurement accuracy, sf the scale factor of the image, $f$ is the focal length of the camera, b' is the image base and GSD is the ground sampled distance.

The UltracamD has a focal length of $101 \mathrm{~mm}$, the GSD of the images is $10 \mathrm{~cm}$ with a forward overlap of $60 \%$ and side lap of $30 \%$, pixel size is 9 microns. The average parallax measurement accuracy of large format digital cameras is in the range of 0.46 to 0.5 pixels (Hohle, 2011). Using the above formulae, the theoretical elevation measurement accuracy for images acquired using UltracamD at $10 \mathrm{~cm}$ GSD is $18.7 \mathrm{~cm}$.

\subsection{Quality Metrics}

The quality of the final DTM derived from Large format digital camera images depends on quality of the point cloud generated by image matching, filtering algorithm, manual editing, DTM interpolation, terrain type etc. The parameters of significance in the automatic generation of DTM is image pyramids and no. of levels, point matching template, threshold for correlation coefficient and least square matching algorithm. The blunder detection algorithm is part of automatic DSM / DTM generation algorithm. The DTM has been generated from DSM through automatic filtering algorithms and manual editing.

Traditionally the DTM accuracy is reported using check points collected from the field which are limited in number, time consuming and costly. In this study the reliability of near automatic DTM generated for the three study areas from Ultracam-D for an operational project covering an area of nearly $600 \mathrm{Sq}$. Km. using 21,000 check points captured stereoscopically by experienced operators. The DTM accuracy is computed using a set of check points. The planimetry 
position of check points are overlaid on the filtered, interpolated, DTM, the difference in height values between DTM and the check point is used as the measure of the accuracy of the DTM ( Zhilin Li, 1991).

The reliability of the DTM with different terrain types for the three areas using statistical distribution of residuals in terms skewness, standard deviation and linear error at $90 \%$ confidence interval (Fernando J. Aguilar, 2007). The quantitative measures for DTM accuracy is estimated in terms of standard deviation and linear error at $90 \%$ and the results are summarized in Table2

\section{RESULT AND DISCUSSIONS}

The DTMs for the three towns were generated through automatic DSM generation and semi-automatic filtering process. The three study areas were chosen to develop quality metrics of DTM due to their heterogeneous terrain types. More than 21000 independent stereo check points have been collected to validate the accuracy of the DTM covering an area of approximately $600 \mathrm{Sq}$. Km. The accuracies of the DTMs of the three towns are Rajnandgaon: $\sigma=10 \mathrm{~cm}$ and LE90 $=10 \mathrm{~cm}$, Durg Bhilai: $\sigma=19 \mathrm{~cm}$ and LE90 $=25 \mathrm{~cm}$ and Korba: $\sigma=9 \mathrm{~cm}$ and LE90 = $13 \mathrm{~cm}$ (Table-3). The terrain type has a major influence on the DTM generated, terrain areas with built-up, industrial buildings, vegetated canopy, water bodies have to be filtered and the voids have to be interpolated, hence the accuracy of DTM in these location was inferior to the DTM accuracy in open areas.

\begin{tabular}{|l|c|c|c|}
\hline Parameters & Rajnandgaon & $\begin{array}{c}\text { Durg- } \\
\text { Bhillai }\end{array}$ & Korba \\
\hline Area (Sq. Km.) & 95 & 234 & 263 \\
\hline $\begin{array}{l}\text { No. of } \\
\text { Check points }\end{array}$ & 2,826 & 10,481 & 7,878 \\
\hline Skewness & 0.253 & -0.283 & 0.292 \\
\hline Kurtosis & 0.884 & 1.679 & 1.574 \\
\hline 25th Percentile & -8.9 & -5.0 & -2.2 \\
\hline 50th Percentile & -3.0 & 5.1 & 0.3 \\
\hline 75 th Percentile & 2.8 & 14.6 & 5.1 \\
\hline $\begin{array}{l}\text { Interquartile } \\
\text { Range }\end{array}$ & 11.7 & 19.6 & 7.3 \\
\hline $\begin{array}{l}\text { Standard } \\
\text { Deviation (cm) }\end{array}$ & 9.7 & 18.5 & 9.1 \\
\hline LE90 (cm) & 9.4 & 24.9 & 13.4 \\
\hline
\end{tabular}

Table-3: DTM Accuracy statistics for three towns

Since large number of check points were collected and due to normal distribution of error measurements, DTMs accuracy is represented in form of standard deviation, Linear Error at $90 \%$ confidence level, skewness and kurtosis. For Rajnandgaon and Korba the skewness is positive (Fig-3 \& Fig.4) whereas it is negative for Durg-Bhillai (Fig-5) which implies that there is asymmetric values of residuals on positive or negative depending on the sign of skewness can be attributed to the interpolation of bare earth near built-up, vegetation, water bodies etc. The positive value of kurtosis in the all the three cases shows peakedness in the distribution since the semiautomatic DTM generated by manual intervention is compared with the stereo check points generated manually.
The achieved DTM accuracy for Rajnandgaon and Korba is well within the theoretical accuracy. In case of Durg-Bhilai, the LE90 is $25 \mathrm{~cm}$ which is approximately 1.3 times the theoretical accuracy which was due to the complexity of the terrain in terms of large number of very huge industrial buildings which has resulted in interpolation of the DTM.

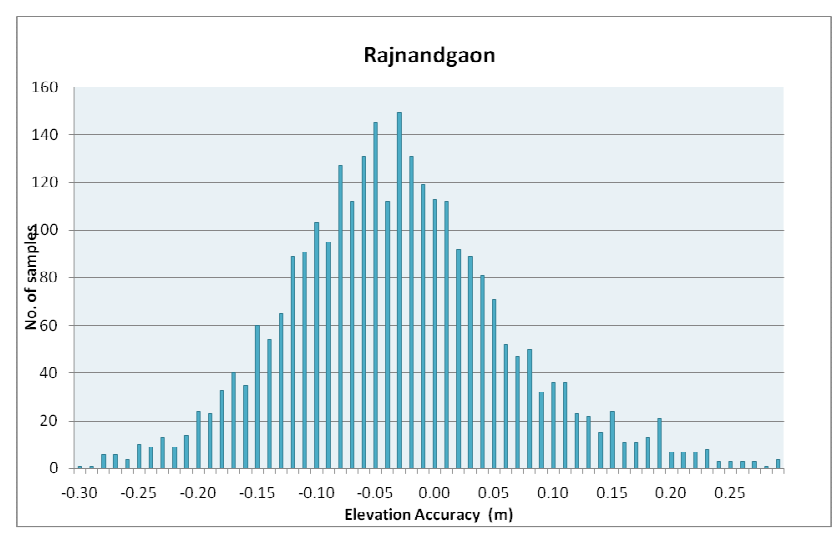

Fig.-3: Rajnandgaon: Frequency distribution of DTM accuracy



Fig.-4: Durg-Bhilai: Frequency distribution of DTM accuracy

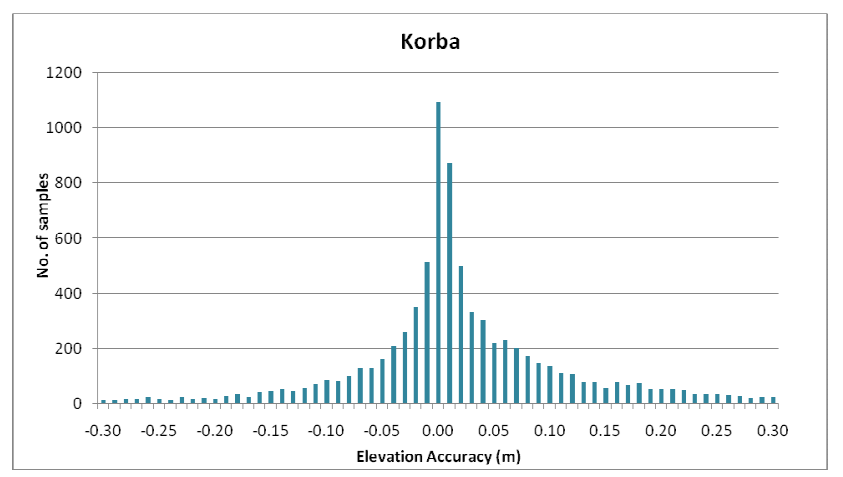

Fig.-5: Korba: Frequency distribution of DTM accuracy

\section{CONCLUSIONS}

The features of Ultracam-D large format digital camera for semi-automatic DTM generation was evaluated and quality metrics of the DTM was estimated. A practical test was carried out in this study to arrive at quality metrics of the DTM 
generated from Ultracam-D. The availability of calibrated camera (factory and filed calibrated), precise misalignment angles between the sensor, GPS and IMU, improved position and orientation system, multispectral images, automatic image matching techniques, filtering algorithms have resulted in the near automatic DTM generation. The reliability of DTM generated by semiautomatic method for different terrain types like flat terrain, vegetated areas, mines, urban built-up and large industrial types was tested for an operational project in terms of elevation accuracy is in close agreement with the theoretical DTM accuracy, provided standard photogrammetric processes and methods are implemented in the generation of DTM.

The semi-automatic method of DTM generation using large format digital camera has revolutionized the process of DTM generation in terms of cost and more importantly one order better turn-around-time (TAT) when compared to the traditional manual DTM methods which is laborious, time consuming and cost ineffective.

With improvements in the specifications of the new digital cameras from Vexcel, Leica, IGI, Trimble and others in terms of resolving power, $\mathrm{b} / \mathrm{h}$ ratio, $\mathrm{CCD}$ dimension (along and across track pixels) etc., DTMs with improved accuracy can be generated with shorter turn-around-time (TAT) in data acquisition and processing domain. To further improve the DTM accuracy the forward overlap can be increased to $80 \%$ with no additional cost and side overlap to $60-80 \%$ with increase in flying effort. The newer cameras allow for big swath width required for decreasing the number of flight lines and allows for increase in sidelap to $60-80 \%$ with minimum effort in data acquisition.

The near automated digital photogrammetry workflow for generation of DTMs with LFDC in terms of accuracies and timelines has resulted in positioning the Large Format Digital Camera as a supplementary sensor for airborne LiDAR coupled with a medium format digital camera for generation of DTMs, close contours and Orthoimages catering to GIS based critical spatial decision support systems.

\section{ACKNOWLEDGEMENTS}

The authors extend sincere thanks to Dr.V.K. Dadhwal, Director, NRSC for his constant support and encouragement in carrying out this study. The authors thank AS\&DMA staff of NRSC for their support during the course of this work.

\section{REFERENCES}

Armin Gruen, 2012. Development and status of image matching in photogrammetry. The Photogrammetric Record 27(137), 3657.

Axelsson, P., 1999. Processing of laser scanner data algorithms and applications. ISPRS Journal of Photogrammetry and Remote Sensing 54 (2-3), 138-147.

Axelsson, P., 2000. DEM generation from laser scanner data using adaptive TIN models. International Archives of the Photogrammetry, Remote Sensing and Spatial Information Sciences XXXIII (Pt. B4/1), 110-117.
Baltsavias, E.P., and M. Hahn, 1999. Integration of image analysis and GIS, International Archives of Photogrammetry and Remote Sensing, 32 (part 7-4-3W6): 12-19.

Fernando J. Aguilar, Francisco Aguera, Manuel A. Aguilar, 2007. A theoretical approach to modeling the accuracy assessment of Digital Elevation Models. Photogrammetric Engineering \& Remote Sensing, Vol.73, No.12, 1367-1379.

George Sithole, George Vosselman, 2004 Experimental comparison of filter algorithms for bare-Earth extraction from airborne laser scanning point clouds. ISPRS Journal of Photogrammetry \& Remote Sensing 59, 85- 101.

Joachim Hohle, 2009. DEM generation using a digital large format frame camera. Photogrammetric Engineering \& Remote Sensing, Vol.75, No.1, January, 2009, pp.87-93.

Joachim Hohle, 2011. On the potential of new digital aerial cameras for DEM generation. The Photogrammetric Journal of Finland, Vol.22, No.2

Leberl, F., Irschara, A., Pock, T., Meixner, P., Gruber, M., Scholz, S., Wiechert, A., 2010. Point Clouds: LiDAR versus 3D vision. Photogrammetric Engineering \& Remote Sensing, Vol.76, No.10, 1123-1134.

Maune, D.F., J. Binder Maitra, E.J.McKay, 2001a. Accuracy standards, Digital Elevation Models and Applications: The DEM Users Manual, American Society for Photogrammetry and Remote Sensing, Bethesda, Maryland.

Nicolas Paparoditis, Jean-Philippe Souchon, Gilles Martinoty, Marc Pierrot-Deseilligny, 2006. High-end digital cameras and their impact on the automation and quality of the production workflow. ISPRS Journal of Photogrammetry \& Remote Sensing. Vol.60, 400-412.

Zhilin Li., 1991.Effects of check points on the reliability of DTM accuracy estimates obtained from experimental tests. Photogrammetric Engineering \& Remote Sensing, Vol.57, No.10, 1333-1340. 